\title{
Universities of Resources for Sustainable Development: Responding to the Current Challenges
}

\author{
Igor Borisovich Sergeev \\ Doctor of Economics, Professor, Federal State Institution of Higher Professional Education \\ "National Mineral University "Mountain" \\ E-mail: si.spb@mail.ru

\section{Olesia Yurievna Lebedeva} \\ PhD in Economics, Federal State Institution of Higher Professional Education \\ "National Mineral University "Mountain" \\ E-mail: ole_spmi@mail.ru
}

\section{Doi:10.5901/mjss.2015.v6n2s4p157}

\begin{abstract}
The problem of sustainable development and the role of universities of resources, which is the scientific and educational base of the mining industry is discussed. Assessment of management effectiveness of national total capital leading mining countries in the OECD and BRICS is given. On the basis of the Hartwick-Solow criterion proposed investment areas of mineral rents in natural, produced and human capital. The main tasks of the universities resources for the sustainable development of countries with large reserves of mineral resources updated.
\end{abstract}

Keywords: Universities of resources; sustainable development; mining industry; mineral rent.

\section{Introduction}

The concept of sustainable development for more than twenty years has been actively discussed by the international community and implemented into the practice of everyday life. State and public institutions jointly establish more stringent environmental and social requirements to business, create different incentive mechanisms of balanced use of human, technological and natural resources. Large and medium-sized companies have begun to develop and implement their own programs of social and environmental responsibility. Many scientists joined to the problem of economy's transition to the principles of sustainable development.

The concept of sustainable development is particular relevant for the mining industry, which in essence is created for the consumption of natural capital and providing the processing industries with raw materials. In the traditional sense, this industry, the business of which consists of the exploration, extraction and primary processing of mineral resources, is not able to have a sustainable development and that it is the mining industry that plays a role of the main destroyer of natural capital. But at the same time, it is clear that the economy without the necessary amount of mineral resources will not be able to function. So is it possible for mining industry to contribute to the sustainable development? If so, that how is it possible?

Mining Universities attempted to be up to this challenge. In 2012, on the initiative of the National Mineral Resources University and the TU Bergakademie Freiberg the World Forum of Universities of Resources on Sustainability (WFURS) was organized with the aim of global implementation of the idea of sustainable development in the life cycles of mineral resources by means of education, research and providing the new perception of raw materials in the society, economy, science and politics. The current members of WFURS are approximately 100 colleges and universities from 60 countries in Europe, Asia, Africa, Australia, North and South America.

It is planned to achieve this goal on the basis of information exchange, educational and scientific cooperation, joint activities of the WFURS members and promotion the sustainability as a technical science in all areas relating to natural resources. Obviously, the goals and objectives have been set correctly. But will the work of forum result in its effective operation? What is required for university of resources for the successful solution of the determined tasks? 


\section{Materials and Methods}

Sustainable development in the economic theory is defined as the exploitation of the society's production capacity at the level that does not lead to their reduction, and subsequent generations are able to use it with no less effectiveness than the previous ones. T. Titenberg noted that as the main criterion of sustainability should be considered observation of the term that the average person of future generations should reside in not less worst conditions, than the average person of present generation (Tietenberg, 1996).

In the second half of the 1970s, J. Hartwick proved that society should invest the rental income from the exploitation of non-renewable resources in reproducible capital in order to maintain the real consumption. Nothing of the rental income should be consumed by the current generation (Hartwick, 1977). R. Solow confirmed that Hartwick rule implies keeping the total capital "safe", so it is a way to achieve sustainability in the use of resources (Solow, 1986). In order to enhance the efficiency and thrift in the management of capital of all generations and T. Paige suggested that each generation should compensate for future generations any irretrievable loss of resources under the Hartwick's rule (Page, 1988).

It is assumed that an artificial, human and natural capital is comparable and interchangeable. The sustainable development is achieved by reinvestment of natural resource rents in the economic capital, which is to be transmitted to future generations in a ratio providing the maintenance of a stable level of consumption. Compensation between generations should be carried out by one-time tax on the current generation and new allocations (investments in resources).

According to the neoclassical economic theory, technological progress is considered as one of the main forces that provides means to achieve economic growth under the conditions of limited resources. The technological progress has at least two forms of influence: by increasing productivity and by replacing resource. Despite the fact that the Hartwick's rule ignores a productivity growth caused by technological progress, its author believes that the growth rate of technological progress exceeds the rate of population growth.

At the beginning of the 1990s R.K. Turner differentiated levels of development resistance in four categories (Turner, 1993):

- Very weak sustainability. Corresponds to the original Hartwick rule and presents the weakest resistance when replacement of used natural resources by human produced capital is theoretically unlimited.

- Weak sustainability. The substitution of natural capital by the produced one is acceptable up to a certain critical point, i.e. the replacement of natural capital by man-made is limited.

- Strong sustainability. The replacement of natural capital used is only permitted for any other natural resource, but not manufactured capital, such as machinery and equipment.

- Very strong sustainability. The substitution of natural capital is unacceptable in essence - neither produced nor other kind of natural.

Achievable levels of sustainable development are the two middle levels: weak and strong sustainability, of which R.K. Turner subsequently mentioned (Turner, 1998) as well as other researchers (Daly, 1995).

In the context of the formation of a knowledge-based economy the role of human capital significantly increases. In essence, human capital, particularly such its components as knowledge, skills, is a limitless production resource. The total introduction of IT into all spheres of economic life bumps up the human resource production to the next level. Today, many technological solutions are embodied not in the equipment and machines, but in many business schemes, knowhow, which are provided by the key employees.

Yet there are no completed developments in assessment of the effectiveness of investments in human capital, but according to many indirect indicators, it is clear that those countries that invest heavily in the social sector, education, science, achieve better economic performance. The modern view on resource management for sustainable development of the society is not limited to the use and reproduction of natural and produced capital. The importance of human capital has increased. It is essential to develop a whole range of theoretical and practical approaches to the problem of its effective use and expanded reproduction. And universities play the extremely important role as research and education centers.

The fundamental question of the economic theory of sustainable development is how to manage aggregate (natural, manufactured and human) capital of present and future generations so that it would grow quantitatively and would not deteriorate qualitatively. In other words, how to manage the processes of intergenerational sustainability. Rationality and efficiency in managing the total capital in long-term periods involving many generations is the basic principle of sustainable development as defined by the UN Commission on Environment and Development (United Nations Conference ..., 1992). Using the resources, primarily natural capital (which includes mineral resources), by every 
previous generation, to some extent makes it impossible for the future generations to use the same resource. This is essential for the proper determination of the permissible scope and nature of the mining industry.

\section{Results and discussion}

Rich mineral resource potential is not uniquely a positive factor for sustainable development of any country. In the context of short-sighted economic policies natural resources begin to perform not only positive but also negative role in the socioeconomic development. In the contrary, with the right understanding of the importance of each economic resource, when the adequate assessment is provided for not only their modern production value but also for its ability to reproduce in a more perfect quality (which is more relevant to human capital), natural-resource potential is becoming a powerful creative factor for sustainable development.

The world's leading centers of the mining industry are the US, Canada, Australia, China, Russian Federation, South Africa, Brazil. These countries have not only developed exploration and mining industry, but also have rich mineral base. In particular, China is the world leader in the production of coal, iron ore, cooper, nickel, gold, cobalt, cadmium, vanadium. United States - the largest producer of natural gas, beryl, kaolin, bromine. The Russian Federation is the world leader in the production of diamond, asbestos, nepheline syenite, palladium (British Geological Survey. 2012, p.7). The first three countries are the largest members of OECD, the last three - BRICS (Brazil, Russia, India, China, South Africa). In this research, we did not consider oil-exporting countries, as they have a pronounced export-oriented industry.

The results show that the availability of rich mineral resources base itself is not a guarantee of raw material specialization of the economy. One cannot say that a high proportion of the mining industry in the total national production determines the instability of development. Obviously, the determinative factor is the level of development of mechanisms of distribution and redistribution the mining industry income, and primarily the mineral rent.

In accordance with the modern economic theory mineral resources generate income to its owner in the form of mineral rent. The industrial use of mineral resources involves two subjects: the owner of the subsoil and the enterprise conducting exploration or exploitation of the deposit. This fact determines the formation of the total income that is to share: the owner of the subsoil - mineral rent; enterprise - entrepreneurial income in the form of profit. Generally, the economic rent is a payment for the resource market supply of which is strictly limited. Mineral rent is a special case of economic rent, but it is the mineral rent that determines the level and quality of the resource base of the economy.

The analysis of the sustainability development results of economies shows that the best results according to the Hartwick-Solow criterion belong to member countries of OECD with high-income rate. BRICS countries have significantly less efficiency in terms of the use of mining companies' income. During the period from 1990 to 2010, the structure of the total capital in Russia and China is difficult to determine as satisfactory. In Russia, produced capital remained at the same level while the share of natural capital was reducing and the share of human capital increased slightly. In China, there was a very sharp increase in produced capital harmfully to the both natural and human ones. (Table 1).

Table 1. Natural, Produced and Human capital per capita in millions US\$ of constant 2005.

\begin{tabular}{|l|c|c|c|c|c|c|}
\hline & \multicolumn{3}{|c|}{1990} & \multicolumn{3}{c|}{2010} \\
\hline & Natural capital & Produced capital & Human capital & Natural capital & Produced capital & Human capital \\
\hline Australia & 36,4 & 16,0 & 47,6 & 23,7 & 27,0 & 49,3 \\
\hline Canada & 36,0 & 14,3 & 49,6 & 25,4 & 21,4 & 53,2 \\
\hline USA & 9,0 & 16,5 & 74,5 & 6,0 & 24,7 & 69,3 \\
\hline Russian Federation & 53,9 & 17,3 & 28,8 & 49,7 & 17,5 & 32,8 \\
\hline Brazil & 41,0 & 15,4 & 43,6 & 27,8 & 17,7 & 54,6 \\
\hline South Africa & 26,5 & 17,3 & 56,2 & 16,7 & 20,0 & 63,3 \\
\hline China & 42,0 & 8,4 & 49,6 & 21,2 & 36,7 & 42,1 \\
\hline
\end{tabular}

Source: Inclusive Wealth Report 2014.

In terms of Inclusive wealth per capita, the OECD countries are significantly ahead of the largest producers of minerals from the BRICS (Figure 1). As for Australia, Canada and China, the gap is almost 12 times size. In general, this indicator increases in all countries under consideration, although it increases to a small extent. At the same time, it should be noted the qualitative changes in the value of produced and human capital. However, if more or less precise methods of evaluation of natural and produced capital exist, it is quite difficult to consider the reliability of estimation of human capital. 
Therefore, the value of human capital is probably overestimated.

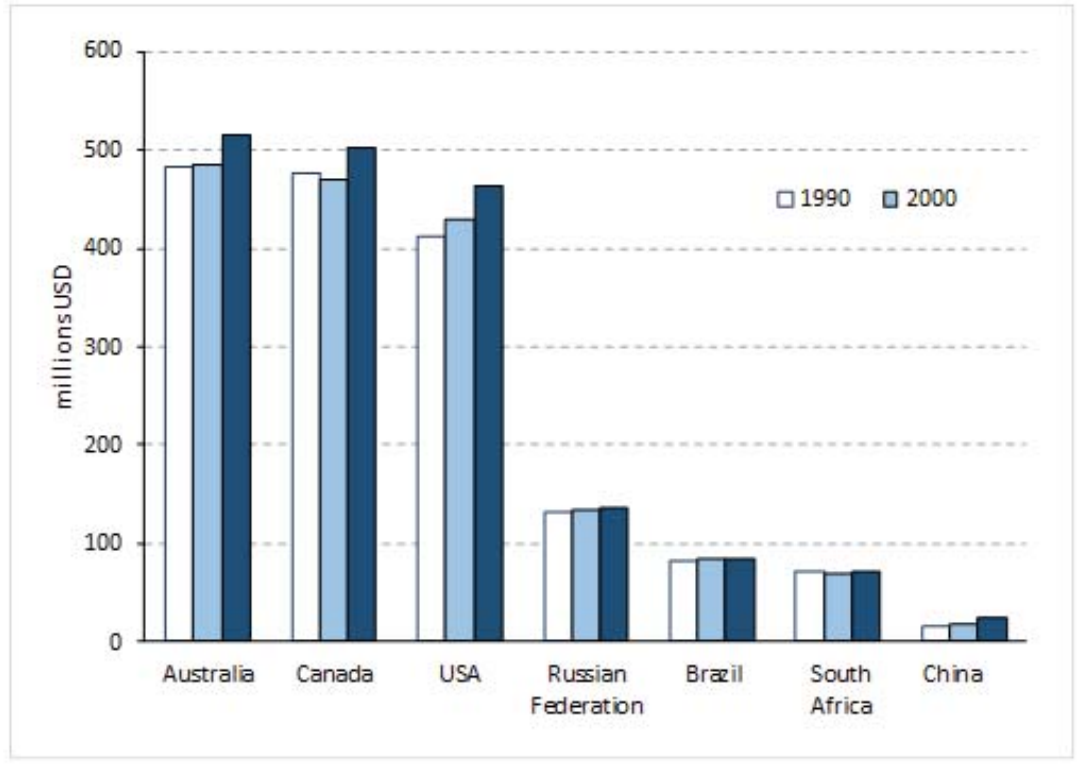

Figure 1. Inclusive wealth per capita in millions US\$ of constant 2005

Source: Inclusive Wealth Report 2014.

The division of the total capital into three abovementioned components is the supposition necessary for understanding the processes of substitution of one type of capital by another one. Of course, this division is very relative. The exploration, mining and service companies that make up the mining complex accumulate for its activities produced capital as well as human and natural forms of capital. And its management largely determines the sustainability of not only this sector of economy but also of the whole society.

Universities WFURS, studying the processes of exploration, extraction, and preparation and processing of primary raw materials pay attention to the fact that these processes lead to a substantial interference in the natural, socio-cultural, environmental and economic systems and communications, and despite the great efforts, these processes still have adverse consequences.

In this regard, WFURS identified a number of its priorities, including: the development and promotion of innovative strategies of educational programs aimed at sustainable development; research and practical development for the mining industry; training and consulting company's personnel regarding the implementation of the sustainable development principles; coordinate the activities of the universities in this direction; holding regular conferences on sustainability, etc.

Currently, countries with raw material dependence have unsustainable development - natural capital is exploited extensively, but virtually mineral rent is invested neither in researching new technology nor in capital of knowledgeintensive and environmentally friendly industries. Income from the development of mineral deposits is being spent on consumption or is being invested in foreign assets, as a rule, in the territory of OECD. Therefore, the solution to this complex problem should be divided into two parts: a reorientation of use of mining rents from consumption to investment; and increasing the investment flow in countries producing mineral resources.

The problem of capital flows to the economically developed countries and, as a consequence, increasing international differentiation according to the level of well-being, has a long history. Many economists and politicians have been trying to find solution to this problem so far. But it should be noted that the existence of this still unsolved problem is a strong deterrent to achieving a sustainable development.

The solving of the other part of the problem of how to get on the path of sustainable for countries with raw material dependence is associated with a thoughtful and balanced distribution of mineral rent. In our opinion, it is necessary to invest it primarily in a country where it is produced, as follows (Figure 2): 


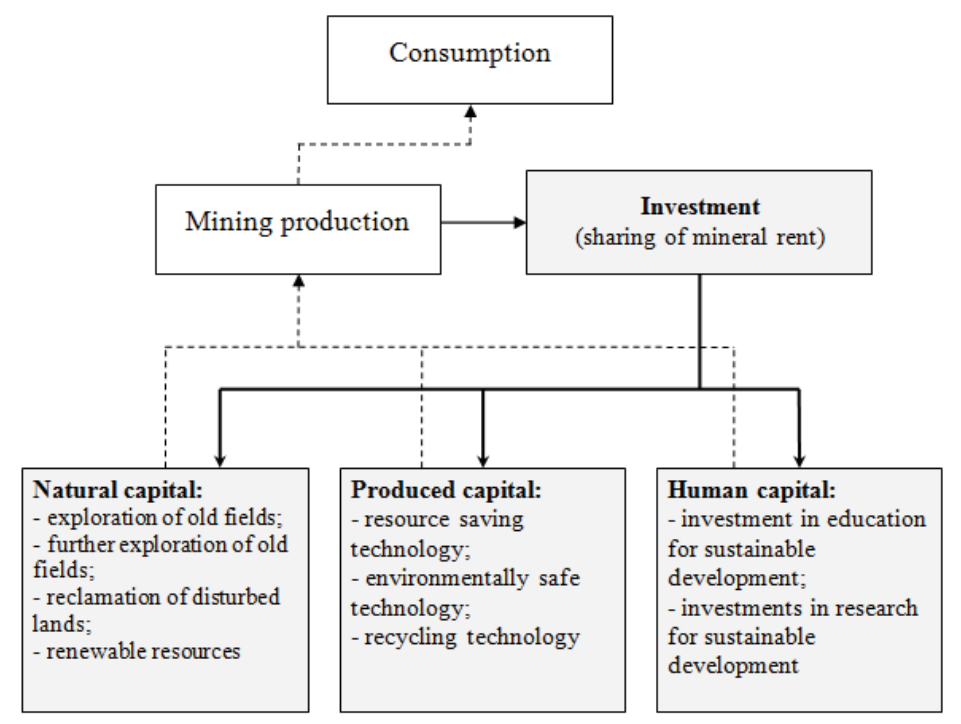

Figure 2. The model of distribution of mineral rent

It is extremely difficult for the government and the industry to solve this problem effectively without adequate scientific and educational support. In this case, the help of universities is extremely useful. Specific efforts of universities, on which they should be focused, can be grouped as follows.

I. In the field of research: systematization (by assistance of partner companies) of relevant scientific, technical and administrative business problems and involvement of scientists in solving them; the formation of temporary research teams comprising of companies' representatives and universities; promotion of promising research and development for introduction into production.

II. In education: coordination of university basic educational programs' formation process, as well as training programs with companies; development of contacts with the leading scientists and experts for their periodic involvement in solving educational problems.

III. In the consulting industry: expert and consulting support of partner companies to meet current industrial, economic and administrative challenges; consulting and organizational support of the scientific and technical activities, conferences and seminars on the innovative development of the mineral resources sector, the mining business and control of resource exploitation.

Thus, the integrated efforts of the governments, the mining industry and universities certainly will be more effective and the objective of sustainable development of mining specialized countries can be finally resolved. And in this case, such a new institutional formation as WFURS, which is systematically engaged in promotion of innovative strategies of educational programs, research and development for the mining industry, training and consulting companies in the implementation of the principles of sustainable development can and should make a significant and valuable contribution.

\section{Conclusions}

Sustainable development of modern economies and society is impossible without the use of mineral production. The inevitable reduction in natural capital, in terms of non-renewable natural resources should be compensated by expanded reproduction produced and human capital. Redistribution of mineral rents in favor of investment in high technologies, exploration of new fields, and the creation of new knowledge is an essential condition of getting on the path of sustainable development. It is necessary for mining industry to develop fields rationally and apply more efficient and environmentally friendly technologies.

A key role in solving this problem can and should play universities of resources as the major centers of competence and generators of innovative solutions for the mining industry. Deeper differentiation in terms of Inclusive wealth per capita among OECD countries and the rest countries actualizes the appropriateness of the international 
interaction while implementing the principles of sustainable development. WFURS, in this case, it is a unique platform for fruitful cooperation.

\section{References}

Arrow, K., Dasgupta, P., Goulder, L., Mumford, K. \& Oleson, K. (2012). Sustainability and the Measurement of Wealth. Environment and Development Economics, 17, 317-353

British Geological Survey. 2012. World mineral production 2008-2012. Retrieved from: http://www.bgs.ac.uk/mineralsuk/statistics /worldArchive.html

Daly, H. (1995). On Wilfrid Beckerman's critique of sustainable development. Environmental Values. 4, 49-55.

Dasgupta, P. (2009). The welfare economic theory of green national accounts. Environmental and Resource Economics, 42(1), 3-38.

Hartwick, J. (1977). Intergenerational Equity and the Investing of Rents from Exhaustible Resources. The American Economic Review. 67.(5). 972-974.

Inclusive Wealth Report 2014. Measuring progress toward sustainability. Cambridge University Press. Retrieved from: http://inclusivewealthindex.org/\#get-the-iwr-2014-report

Page, T. (1988).Intergenerational equity and the social rate of discount. V. Kerry Smith (ed.). Environmental resources and applied welfare economics. Resources for the Future, Washington DC.

Sarma J., Naresh, G. (2001). Mineral Taxation around the World: Trends and Issues. Asia-Pacific Tax Bulletin, Jan.

Solow, R. (1986). On the intergenerational allocation of natural resources. Scandinavian Journal of Economics, 88(1), 141-149.

Tietenberg, T. (1996). Environmental and Natural Resource Economics. 4th ed. Harper Collins College Publishers, New York.

Turner, R. (1993). Sustainability: principles and practice. Sustainable environmental economics and management: principles and practice. Belhaven Press, London, 3-36.

Turner, R., Adger W. \& Lorenzoni I. (1998). Towards Integrated Modelling and Analysis in Coastal Zones: Principles and Practices, LOICZ Reports \& Studies, 11, 122.

United Nations Conference on Environment and Development 1992. The Rio Declaration. UNCED Document A, CONF. 155, 5, Rev.1, June 13.

World Forum of Universities of Resources on Sustainability: Constitution. Final 21 October 2014. Retrieved from: http://www.worldforum-sustainability.org/wp-content/uploads/2013/10/141021FinalCharterAsApproved_spacescorrectedPagac.pdf 
